\title{
Effects of Vitamin D on COVID-19 Infection and Prognosis: A Systematic Review
}

This article was published in the following Dove Press journal:

Risk Management and Healthcare Policy

\author{
Hiwot Yisak (D) \\ Amien Ewunetei $\mathbb{B}^{2}$ \\ Belayneh Kefale $\mathbb{D}^{2}$ \\ Melkalem Mamuye (D) \\ Fentaw Teshome ${ }^{1}{ }^{1}$ \\ Birhanie Ambaw' \\ Getachew Yideg Yitbarek $\mathbb{D}^{3}$ \\ 'Department of Public Health, College of \\ Health Sciences, Debre Tabor University, \\ Debre Tabor, Ethiopia; ${ }^{2}$ Department of \\ Pharmacy, College of Health Sciences, \\ Debre Tabor University, Debre Tabor, \\ Ethiopia; ${ }^{3}$ Department of Biomedical \\ Science, College of Health Sciences, \\ Debre Tabor University, Debre Tabor, \\ Ethiopia
}

Introduction: Vitamin D status is related to risks of influenza and respiratory tract infections. Vitamin D has direct antiviral effects primarily against enveloped viruses, and coronavirus is an enveloped virus. The 2019 coronavirus disease had a high mortality rate and impacted the whole population of the planet, with severe acute respiratory syndrome the principal cause of death. Vitamin D can adequately modulate and regulate the immune and oxidative response to infection with COVID-19. The goal of this systematic review was thus to summarize and decide if there were a link between vitamin D status and COVID-19 infection and prognosis.

Methods: The protocol of this study is documented in the Prospero database and can be accessed with the protocol number CRD42020201283. PubMed and Google Scholar were used for a literature search from August 2020 to September 2020. We restricted the year of publication of reviewed articles to 2019-2020, and the selected language was English. Studies that used secondary data, feedback, or analysis of reviews were removed. To assess the standard of studies included, the Grading of Recommendations, Assessment, Development, and Evaluation (GRADE) method was used.

Results: Of the nine studies reviewed, seven (77.8\%) showed that COVID-19 infection, prognosis, and mortality were correlated with vitamin D status.

Conclusion: Most of the articles reviewed showed that blood vitamin D status can determine the risk of being infected with COVID-19, seriousness of COVID-19, and mortality from COVID-19. Therefore, maintaining appropriate levels of Vitamin D through supplementation or natural methods, eg, sunlight on the skin, is recommended for the public to be able to cope with the pandemic.

Keywords: COVID-19, vitamin D, prognosis, infection, mortality

\section{Plain-Language Summary}

- Vitamin D is a fat-soluble vitamin.

- It is already established that vitamin D is associated with risks of influenza and respiratory tract infection.

- Currently, COVID-19 poses a higher death rate and impacts the world population as a whole.

- There are inadequate systematic reviews that summarize the relationship of vitamin D to infections with COVID-19 and prognosis.

- The goal of this systematic review was to summarize and decide if there were a relationship between vitamin D status and COVID-19 infection and prognosis.

Department of Public Health, College of Health Sciences, Debre Tabor University,

Debre Tabor, Ethiopia

Tel +25I-9l-372-8949

Email hyisak@yahoo.com
- We performed an inclusive search for literature from August to September 2020. Some newly published articles after the search were also considered, and articles published from 2019 to 2020 were included. 
- In sum, $77.8 \%$ of the articles reviewed showed that vitamin D status was related to the infection, prognosis, and mortality of COVID-19.

- In conclusion, most of the articles showed that blood vitamin D status could be used to assess the risk of catching COVID-19, the seriousness of COVID-19 disease, and death. Therefore, maintaining appropriate levels of vitamin D through supplementation or naturally through sunshine is recommended for the public to cope with the pandemic.

\section{Introduction}

Vitamin D is a lipid-soluble vitamin that is essential for maintaining good health, growth, and strong bones. It can be produced in the skin with the help of exposure to sunlight. Most foods naturally contain little vitamin D, but some are fortified with vitamin D. Hypovitaminosis $\mathrm{D}$ is associated with cardiovascular disease, diabetes mellitus type 2, metabolic syndrome, cancer, and increased death rates. In addition, depression and decreased cognitive function are associated with vitamin D deficiency. Advanced age and high body-fat mass lead to an increased risk of deficiency of vitamin D. ${ }^{1}$ A mild vitamin D deficiency does not cause symptoms, but may cause weakness, aches, and pain in general. A more serious deficiency can cause problems, such as osteomalacia in adults and rickets in children. ${ }^{2,3}$ Vitamin D has been recognized as essential to the skeletal system and plays a major role in monitoring the immune system, perhaps including immuno reactions to viral infection. The severity of influenza and respiratory-tract infections may be increased by vitamin D insufficiency. Cell-culture studies have shown that vitamin D has a particular role against enveloped viruses and direct antiviral effects. This might be because of the ability of vitamin $\mathrm{D}$ to upregulate human beta $\beta$-defensin 2 and antimicrobial peptide $37,{ }^{4}$ and it is known that coronavirus is an enveloped virus. ${ }^{5}$ According to epidemiological and clinical studies, vitamin D safeguards against tuberculosis and plays a critical role in the defense against HIV and respiratory infections. ${ }^{6,7}$ Increased secretion of the antimicrobial peptide cathelicidin, reduced production of chemokine, inhibition of dendritic cell activation, and alteration of T-cell activation are effects of vitamin $\mathrm{D}$ within the lungs. For host responses to infection and the incidence of allergic lung diseases, such as asthma, these cellular effects are important. Research has shown that vitamin D deficiency predisposes one to infections of the viral respiratory tract and mycobacterial infections, and thus vitamin D can play a role in the development and treatment of asthma. ${ }^{6,8}$

COVID-19 has a high death rate and affects almost the entire population of the world. The world population is still worried, because there is no exact and definitive treatment for this ailment. Serious acute respiratory syndrome is the cause of death, as a consequence of an exacerbated inflammatory reaction followed by uncontrolled oxidative stress and a lung-level inflammatory reaction. ${ }^{9}$ Vitamin $\mathrm{D}$ could be a good option to tackle this problem, considering that it can balance and control immunity and oxidative reactions against COVID-19 infection. The renin-angiotensin system is related to the resulting inflammatory reaction, which has a principal function in the physiopathology of COVID-19 infection, and it might be downregulated by vitamin $\mathrm{D}$ in various organs. ${ }^{10,11}$ During the COVID-19 pandemic, a high proportion of moderate-severe cases and a high fatality rate have been observed among the elderly. Chronic noncommunicable diseases, obesity, and overweight are related wtoith vitamin $\mathrm{D}$ deficiency. ${ }^{12}$ A randomized pilot study that assessed the effect of calcifediol treatment and bestavailable therapy versus best-available therapy on intensive careunit (ICU) admission and mortality among patients hospitalized for COVID-19 demonstrated that administration of a high dose of calcifediol or 25-hydroxyvitamin D $(25[\mathrm{OH}] \mathrm{D})$, the main metabolite of vitamin $\mathrm{D}$, significantly reduced the need for ICU treatment of patients requiring hospitalization due to proven COVID-19. ${ }^{13}$

Correlational and cross-sectional observational studies performed in various parts of the world have shown that vitamin D-deficient areas have a higher prevalence of COVID-19 patients. $^{14-18}$ Descriptive and observational studies have reported that higher prevalence of mortality and critical cases of COVID-19 are more common among vitamin D-deficient patients. ${ }^{19,20}$ A narrative review aimed at collecting the literature available on involvement of vitamin D status in the pathogenesis of COVID-19 and the putative utility of vitamin D supplementation in therapeutics concluded that poor vitamin D status seems to be associated with an increased risk of infection, whereas age, sex, and comorbidities seemed to play a more important role in COVID-19 severity and mortality. ${ }^{21}$ There is a need to generalize and summarize the findings of individual studies to synthesize evidence that helps make COVID19 prevention effective. Therefore, the purpose of this study was to undertake a systematic review to summarize 
and determine whether there is a relation between vitamin D status and COVID-19 infection and prognosis.

\section{Methods}

\section{Registration}

The protocol was recorded in the Prospero database (CRD42020201283).

\section{Search Strategy}

A comprehensive literature search of PubMed and Google Scholar was carried out from August to September 2020 using parallel search strings tailored to the specifications of each database.Identification of publications, data extraction, and reporting of results for the review were planned as per PRISMA guidelines. Search terms used were "vitamin D" OR "25-hydroxy vitamin D" OR "micro-nutrient" OR "fat soluble vitamin" OR "lipid soluble vitamin" AND "COVID-19" OR "coronavirus" or "corona" OR "SARSCoV2" AND "infection" OR "prognosis". To find extra papers, we reviewed the reference lists of published studies. Three of the authors (AE, HY, and BK) independently found and selected papers on the databases following the eligibility requirements and without the use of filters.

\section{Eligibility Criteria}

Eligibility requirements were papers presenting original data on vitamin D status and COVID-19, research done on adults, not published before 2019, and in English. Form of analysis was not considered a criterion, and it was sufficient to select a study if of vitamin D status andCOVID-19 prognosis and infection were assessed or compared. Studies using secondary data, reviews of reviews, and those with no ORs or RRs were not included.

\section{Evaluation of Study Quality}

To determine the quality of studies included in this review, the Grading of Recommendations, Assessment, Development, and Evaluation (GRADE) system was used. This tool evaluates variables that may decrease (risk of bias, inconsistency of results, inaccuracy, indirect evidence, and publication bias) or increase (magnitude of effect and fewer confounders) the quality of each study. Score for experimental studies begin at 4 , and for observational studies scores begin at 2 (low quality). According to the magnitude of the factor, 1-2 points are deducted for any current factor that can decrease the quality of the study. The presence of factors that increase the quality of evidence adds 1-2 points to the initial score. Studies were classified as low ( $<2$ points) and good quality ( $>2$ points) for the final sum. We did not recognize publication bias or selective study reporting. In the review, studies scoring $>2$ points were included.

\section{Selection and Identification of Studies}

All study results were imported into Covidence software for screening. First, duplications were removed. Then, studies were screened based on the theme they addressed by reading titles and abstracts. In the event of disagreement between the authors, a study was reevaluated and doubts discussed until consensus was reached. Full texts of papers were scanned manually and with EndNote.

A total of 337 studies were obtained. Of these, 111 duplicates were identified and removed. In sum, 160 articles were excluded because they were irrelevant. After assessment of the full texts of the remaining 66, 16 were left. An additional nine were excluded because of poor quality and lack of reporting on outcome of interest. Additionally, two studies published after the search period were included. As such, nine unique studies were eligible and enrolled for final review (Figure 1).

\section{Results}

\section{Studies Included}

In sum, 337 papers were eligible, 226 remained for screening after deletion of duplicates, and 66 papers qualified for full-text review based on the initial title and abstract screening. Finally, nine were included for the final review after the addition of recently published works and based on the eligibility criteria (Figure 1 ).

The nine studies covered 1,005,042 study participants (COVID-19 patients). The number of participants in this study differed from a smaller retrospective observational study in Italy of 42 COVID-19 patients $^{22}$ and a larger study involving $1,000,000$ study participants ${ }^{23}$ in 20 European countries. Regarding study setting, two were conducted in Italy, one in 20 European countries, one in the US, one in the UK, one in Israel, two multinational, and one in Spain. Methodological quality scores of all studies ranged $5-8.5$ on the Newcastle-Ottawa scale. In two of the nine studies, important associations of vitamin D with COVID-19 infection, severity, and mortality was not demonstrated (Table 1). 


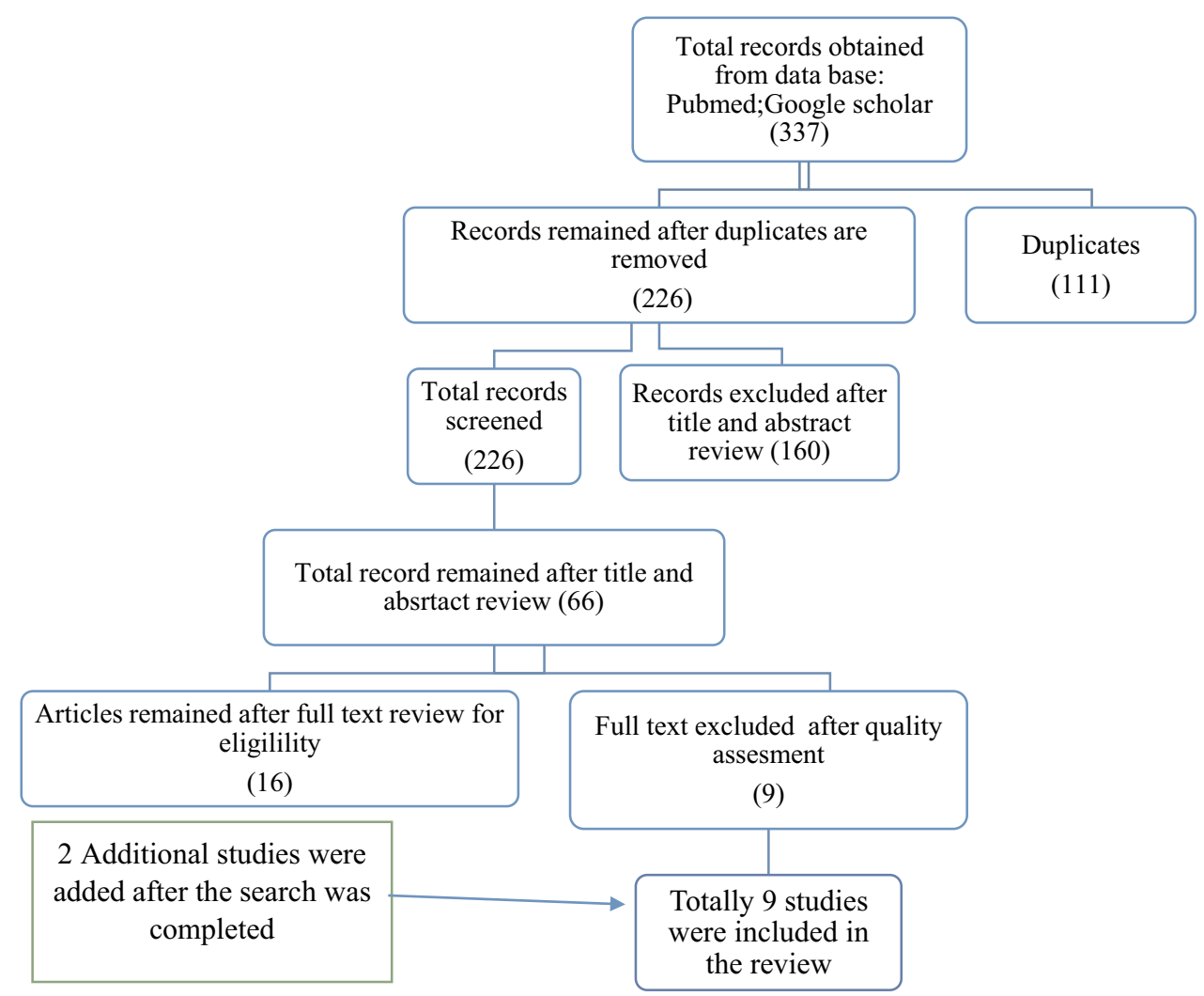

Figure I Flow diagram showing the method of selection for papers included in this systematic review.

Risk Factors of COVID-I 9 Infection, Severity, and Mortality Identified

Analysis of data from COVID-19 patients diagnosed at the University of Cincinnati health system showed that hospitalization of COVID-19 patients was associated with vitamin D deficiency (OR 1.77, 95\% CI 1.072.93). ${ }^{24}$ In addition, disease severity was associated with vitamin D deficiency (OR 1.95, 95\% CI 1.073.56), and odds of admission to ICU were higher in vitamin $\mathrm{D}$-deficient individuals (OR 2.55, 95\% CI 1.28-5.08). ${ }^{24}$ Daneshkhah et al reported that elimination of severe vitamin D deficiency reduced the risk of high CRP levels (OR 2), which may be used as a surrogate marker of cytokine storm, estimated to result in a potential reduction in severe COVID-19 cases. ${ }^{25}$ Moreover, a retrospective study in 20 European countries found a significant correlation of levels of mean vitamin D status with COVID-19 cases $(P=0.033)$, but not with death $(P=0.123) .^{23}$

A population-based study in Israel found that low vitamin $D$ levels were associated with increased likelihood of COVID-19 infection (AOR 1.50, 95\% CI 1.13-1.98; $P<0.001){ }^{26}$ Similarly, a study assessing COVID-19 in
Parkinson's disease patients living in Lombardy, Italy found that patients affected by COVID-19 were less likely to have received vitamin Dsupplementation than uninfected patients (AOR 0.56, 95\% CI 0.32-0.99; $P=0.048) .{ }^{27} \mathrm{~A}$ study at the Policlinico di Bari, Italy among adult inpatients demonstrated that mortality was more common among severely vitamin D-deficient patients (OR 5,681, 95\% CI 1,114-28,974; $P=0.037$ ). ${ }^{22}$

A randomized pilot study demonstrated that administration of a high dose of calcifediol or $25(\mathrm{OH}) \mathrm{D}$, the main metabolite of vitamin $\mathrm{D}$, significantly reduced the need for ICU treatment of patients requiring hospitalization due to COVID-19: of 50 patients treated with calcifediol, one required admission to the ICU (2\%), while of 26 untreated patients, 13 required admission $(50 \%, p<0.001)$. The univariate risk-estimate OR for ICU patients with calcifediol treatment versus without calcifediol treatment was 0.02 (95\% CI $0.002-0.17)$, while the multivariate risk-estimate OR after adjustment for hypertension and type 2 diabetes mellitus was 0.03 (95\% CI $0.003-0.25) .^{13}$

Increased age, ${ }^{22,24,26,28}$ male sex $^{26,28,29}$ obesity, overweight, high $\mathrm{BMI},{ }^{27,29,30}$ and presence of 
Table I Characteristics of Studies Included

\begin{tabular}{|c|c|c|c|c|c|c|}
\hline $\begin{array}{l}\text { Authors, } \\
\text { Years }\end{array}$ & Country & Setting & Design & Period & Sample Size & Effect of Vitamin D on COVID-I9 \\
\hline Mendy et al & USA & UC & CS & $\begin{array}{l}\text { March I3- } \\
\text { May 3I, } \\
2020\end{array}$ & 689 & $\begin{array}{l}\text { Vitamin D was linked with length of hospital } \\
\text { stay, disease harshness, and admission to } \\
\text { ICU. }\end{array}$ \\
\hline Hastie et al & Multinational & UK Biobank & CS & $\begin{array}{l}\text { March 16- } \\
\text { April 14, } \\
2020\end{array}$ & 449 & $\begin{array}{l}\text { Vitamin D status was not linked with } \\
\text { COVID-19 status. }\end{array}$ \\
\hline $\begin{array}{l}\text { Raisi- } \\
\text { Estabragh } \\
\text { et al }\end{array}$ & UK & UK Biobank & PC & $\begin{array}{l}16 \text { March- } \\
18 \text { May, } \\
2020\end{array}$ & 1326 & $\begin{array}{l}\text { No important relation between the } 25(\mathrm{OH}) \\
\text { D status adjusted for the season and } \\
\text { COVID-19 positivity. }\end{array}$ \\
\hline $\begin{array}{l}\text { Daneshkhah } \\
\text { et al }\end{array}$ & Multinational & Nationwide & CS & $\begin{array}{l}\text { March 2I- } \\
\text { April I, } \\
2020\end{array}$ & 793 & $\begin{array}{l}\text { Patient-level CRP information was used as a } \\
\text { cytokine-storm proxy marker and } \\
\text { interrelated with vitamin D status, and } \\
\text { indicated a possible correlation between } \\
\text { vitaming D status and COVID-19 severity. }\end{array}$ \\
\hline Ali & $\begin{array}{l}20 \text { European } \\
\text { countries }\end{array}$ & $\begin{array}{l}\text { Global } \\
\text { Coranz } \\
\text { Virus data } \\
\text { portal }\end{array}$ & $\mathrm{RC}$ & $\begin{array}{l}\text { April 8- } \\
\text { May 20, } \\
2020\end{array}$ & $1,000,000$ & $\begin{array}{l}\text { A significant correlation was observed for } \\
\text { levels of mean vitamin } D \text { with COVID-19 } \\
\text { cases }(p=0.033) \text { but not with death } \\
(P=0.123) \text { per million of population }\end{array}$ \\
\hline Merzon et al & Israel & $\begin{array}{l}\text { Leumit } \\
\text { Health } \\
\text { Services } \\
\text { (LHS) } \\
\text { database }\end{array}$ & CS & $\begin{array}{l}\text { February } \\
\text { I-April } 30 \\
2020\end{array}$ & 782 & $\begin{array}{l}\text { An independent risk factor for COVID-I9 } \\
\text { infection and hospitalization appeared to be } \\
\text { low plasma } 25(\mathrm{OH}) \mathrm{D} \text { levels. }\end{array}$ \\
\hline Fasano et al & Italy & $\begin{array}{l}\text { Single } \\
\text { tertiary } \\
\text { center in } \\
\text { Lombardy }\end{array}$ & $\begin{array}{l}\text { case- } \\
\text { controlled } \\
\text { survey }\end{array}$ & $\begin{array}{l}\text { Three } \\
\text { months }\end{array}$ & 105 & $\begin{array}{l}\text { COVID-19 patients were vitamin D } \\
\text { nonsupplemented than unaffected patients. }\end{array}$ \\
\hline $\begin{array}{l}\text { Carpagnano } \\
\text { et al }\end{array}$ & Italy & $\begin{array}{l}\text { Policlinico di } \\
\text { Bari }\end{array}$ & $\begin{array}{l}\text { Retrospective, } \\
\text { observational } \\
\text { study }\end{array}$ & $\begin{array}{l}\text { March II- } \\
\text { April 30, } \\
2020\end{array}$ & 42 & $\begin{array}{l}\text { There was a significantly greater mortality } \\
\text { risk due to COVID-19 in patients with } \\
\text { severe vitamin D deficiency. }\end{array}$ \\
\hline Entrenas et al & Spain & $\begin{array}{l}\text { Spanish } \\
\text { patients } \\
\text { hospitalized } \\
\text { for COVID- } \\
19\end{array}$ & RCT & Five days & 76 & $\begin{array}{l}\text { Administration of a high dose of calcifediol } \\
\text { or } 25(\mathrm{OH}) \mathrm{D} \text { significantly reduced the need } \\
\text { for ICU treatment of patients requiring } \\
\text { hospitalization due to proven COVID-19. }\end{array}$ \\
\hline
\end{tabular}

Abbreviations: UC, University of Cincinnati; RCT, randomized controlled trial; CS, cross-sectional; RC, retrospective cohort; PC, prospective cohort.

comorbidities $^{24,26-28}$ are recognized risk factors for death and severity among COVID-19 patients. In addition, ethnicity of non-Hispanic black/Hispanic, ${ }^{24}$ nonwhite, South Asian, ${ }^{30}$ and BAME, ${ }^{29}$ higher levels of creatinine, troponin, and IL6, ${ }^{22}$ higher Townsend deprivation score, ${ }^{29}$ and household overcrowding ${ }^{29}$ are independent predictors of severity or mortality among patients with COVID-19 (Table 2).

\section{Discussion}

Seven (77.8\%) articles showed that the status of vitamin D status was related to COVID-19 infection, severity, and death. $^{22,24-28}$ Two $^{29,30}$ failed to show an association. This might be because the vitamin D levels in these studies were measured a long ago, before the patients were infected with COVID-19, and might not represent actual vitamin D levels after infection with COVID-19. 
Table 2 Factors Associated with Seriousness of or Death by COVID-19

\begin{tabular}{|c|c|c|}
\hline Author Name & $\begin{array}{l}\text { Factors Associated with } \\
\text { Severity or Mortality Due } \\
\text { to COVID-19 }\end{array}$ & $\begin{array}{l}\text { Sign of } \\
\text { Association }\end{array}$ \\
\hline Mendy et al & $\begin{array}{l}\text { Age } \\
\text { Non-Hispanic/Hispanic } \\
\text { Tobacco smoking } \\
\text { Vitamin D level } \\
\text { Hematologic disorder } \\
\text { With comorbidities: DM, } \\
\text { hypercholesterolemia, asthma, } \\
\text { COPD, CKD, CVD, } \\
\text { osteoarthritis }\end{array}$ & $\begin{array}{l}+ \\
+ \\
+ \\
+ \\
+ \\
+\end{array}$ \\
\hline Hastie et al & $\begin{array}{l}\text { Being male } \\
\text { Socioeconomic status } \\
\text { Self-reported health status } \\
\text { Age at assessment } \\
\text { Overweight/obese } \\
\text { Non-Caucasian and South } \\
\text { Asians } \\
\text { Vitamin D status }\end{array}$ & $\begin{array}{l}+ \\
- \\
- \\
+ \\
+ \\
+ \\
-\end{array}$ \\
\hline $\begin{array}{l}\text { Raisi-Estabragh et } \\
\text { al }\end{array}$ & $\begin{array}{l}\text { Male sex } \\
\text { BAME } \\
\text { Body-mass index } \\
\text { Townsend deficiency score } \\
\text { Domestic congestion } \\
\text { Vitamin D status }\end{array}$ & $\begin{array}{l}+ \\
+ \\
+ \\
+ \\
+ \\
-\end{array}$ \\
\hline Daneshkhah et al & $\begin{array}{l}\text { Age } \\
\text { Vitamin D level }\end{array}$ & $\begin{array}{l}+ \\
+\end{array}$ \\
\hline Ali & Vitamin D level & + \\
\hline Entrenas et al & Vitamin D level & + \\
\hline Merzonet al & $\begin{array}{l}\text { Age } \\
\text { Male sex } \\
\text { Socioeconomic status } \\
\text { Having dementia } \\
\text { Vitamin D status } \\
\text { CVD } \\
\text { Chronic lung disorder }\end{array}$ & $\begin{array}{l}+ \\
+ \\
- \\
- \\
+ \\
- \\
-\end{array}$ \\
\hline Fasano et al & $\begin{array}{l}\text { Age } \\
\text { COPD status } \\
\text { Obese } \\
\text { Vitamin D-supplementation } \\
\text { status }\end{array}$ & $\begin{array}{l}- \\
- \\
+ \\
+\end{array}$ \\
\hline Carpagnano et al & $\begin{array}{l}\text { Age } \\
\text { Levels of creatinine, troponin, } \\
\text { and IL6 } \\
\text { Vitamin D status }\end{array}$ & $\begin{array}{l}+ \\
+ \\
+\end{array}$ \\
\hline
\end{tabular}

Four of ththe seven ${ }^{23,24,26,27}$ showed positive associations between vitamin D status and SARS-CoV2 infection. Mendy et al found that admitted cases of COVID-19 were more likely to be deficient in vitamin D. ${ }^{24}$ Similarly, a population-based study in Israel found that low vitamin D levels were related to higher likelihood of COVID-19 infection. ${ }^{26}$ A study examining COVID-19 in patients with Parkinson's disease living in Lombardy, Italy found that patients with COVID-19 were less likely to have received vitamin D supplementation than patients who were uninfected..$^{27}$ More importantly, a retrospective study in 20 European countries found a significant correlation between of mean vitamin D levels and COVID-19 cases. $^{23}$ A descriptive study carried out on adults admitted to Inha University Hospital, South Korea that aimed to assess the nutritional status of patients with COVID-19 found extreme vitamin D deficiency in $24 \%$ of patients in the COVID19 group and $7.3 \%$ in the control group. The COVID-19 group showed significantly lower vitamin $\mathrm{D}$ values than the stable control group. ${ }^{14}$

A retrospective cohort study done at the University of Chicago showed that the rate of COVID-19 was higher in a vitamin D-deficient group than a vitamin D-sufficient group. ${ }^{16}$ In addition, a retrospective study of $25(\mathrm{OH}) \mathrm{D}$ plasma concentrations collected from a cohort of Swiss patients recorded significantly lower levels of 25(OH)D on SARS-CoV2 (median value $11.1 \mathrm{ng} / \mathrm{mL}$ )-positive PCR compared with negative patients $(24.6 \mathrm{ng} / \mathrm{mL}) .{ }^{17}$ A correlation study by Kara et al indicated that vitamin D deficiency was a pandemic, especially in Europe, where 40\% were vitamin D-deficient and $13 \%$ severely deficient. A fourfold association was established among incidence of COVID-19, vitamin D deficiency, and latitude in the most frequently affected countries. ${ }^{18}$ This might be because that vitamin $\mathrm{D}$ is mostly formed with the help of sunshine, and many countries in Europe receive little sunlight through the year.

Associations of severity of and mortality from COVID19 with vitamin D status was reported in four ${ }^{13,22,24,25}$ of the seven studies. Analysis of data from COVID-19 patients diagnosed in the University of Cincinnati health system found that the severity of COVID-19 disease was correlated with vitamin D deficiency and the likelihood of ICU admission higher for vitamin D-deficient individuals. ${ }^{24}$ In agreement with this Daneshkhah et al 
found that treating serious vitamin $\mathrm{D}$ deficiency reduced the risk of high CRP levels. ${ }^{25}$ CRP levels are used as a proxy marker of cytokine storm, which is expected to be elevated in severe COVID-19 cases.

Different descriptive and correlational studies are in agreement with the results of the current review. Lau et al revealed that eleven $(84.6 \%)$ ICU patients and four (57.1\%) non-ICU patients had vitamin D insufficiency. Of these, $64.6 \%(n=7)$ had critically low $25(\mathrm{OH}) \mathrm{D}$ $(<20 \mu \mathrm{g} / \mathrm{mL})$ and three had $<10 \mu \mathrm{g} / \mathrm{mL}$. In addition, all these patients were aged $<75$ years and had vitamin D deficiency. ${ }^{1515191520}$ Another retrospective observational study aimed to investigate vitamin D levels and their correlation with COVID-19 severity in West Flanders, Belgium determined by CT, and found higher vitamin D-deficiency rates among severe cases of COVID-19 (58.6\% versus $45.2 \%, P=0.0005)$. A study assessing the prevalence of vitamin $\mathrm{D}$ deficiency in COVID-19 patients also showed that mean serum 25 $(\mathrm{OH}) \mathrm{D}$ levels were an indicator of the seriousness of the disease.

As reported by Carpagnano et al at the Policlinico di Bari, COVID-19 mortality was more prevalent among extremely vitamin D-deficient patients in adults admitted to a respiratory intensive care unit.On survival analysis, extremely vitamin D-deficient patients had a $50 \%$ chance of death after 10 days of hospitalization, whereas those with sufficient vitamin D had a $5 \%$ risk of death $(\boldsymbol{P}=0.019) .{ }^{\mathbf{2 2}}$

\section{Conclusion}

Most of the articles demonstrated that vitamin D status in the blood can determine the chances of catching coronavirus, coronavirus severity, and mortality. Therefore, keeping appropriate blood levels of vitamin D through supplementation or through sunshine exposure is recommended for the public to be able to cope with the pandemic.

\section{Abbreviations}

25(OH)D, 25-hydroxyvitamin D; BAME, Black, Asian and Minority Ethnic; BMI, body mass index; COPD, chronic obstructive lung disease; COVID-19, coronavirus disease 2019; CT, computed tomography; CVD, cardiovascular disease; DM, diabetes milletus; GRADE, Grading of Recommendations, Assessment, Development, and Evaluations; ICU, intensive care unit; iPRISMA, preferred reporting items for systematic reviews and meta-analysis;
RR, relative risk; SARS-CoV2, severe acute respiratory syndrome coronavirus 2 ; VDD, vitamin D deficiency.

\section{Data availability}

All data are available.

\section{Author Contributions}

All authors made a significant contribution to the work reported, whether in the conception, study design, execution, acquisition of data, analysis, interpretation, or all these areas, took part in drafting, revising, or critically reviewing the article; gave final approval to the version to be published, have agreed on the journal to which the article has been submitted, and agree to be accountable for all aspects of the work.

\section{Funding}

We did not receive any funding for this review.

\section{Disclosure}

The authors report no conflicts of interest for this work.

\section{References}

1. DeLuca HF. Overview of general physiologic features and functions of vitamin D. Am J Clin Nutr. 2004;80(6):1689S-96S. doi:10.1093/ ajen/80.6.1689S

2. Galesanu C, Mocanu V. Vitamin D deficiency and the clinical consequences. Rev Med Chir Soc Med Nat Iasi. 2015;119(2):310-318.

3. Zdrenghea MT, Makrinioti H, Bagacean C, Bush A, Johnston SL, Stanciu LA. Vitamin D modulation of innate immune responses to respiratory viral infections. Rev Med Virol. 2017;27(1):e1909. doi:10.1002/rmv.1909

4. Beard JA, Bearden A, Striker R. Vitamin D and the anti-viral state. $J$ Clin Virol. 2011;50(3):194-200. doi:10.1016/j.jcv.2010.12.006

5. Sturman LS, Holmes KV. Characterization of a coronavirus. Virology. 1977;77(2):637-649. doi:10.1016/0042-6822(77)90488-3

6. Dini C, Bianchi A. The potential role of vitamin D for prevention and treatment of tuberculosis and infectious diseases. Ann Ist Super Sanità. 2012;48(3):319-327. doi:10.4415/ANN_12_03_13

7. Jiménez-Sousa M, Martínez I, Medrano LM, Fernández-Rodríguez A, Resino S. Vitamin D in human immunodeficiency virus infection: influence on immunity and disease. Front Immunol. 2018;9:458. doi:10.3389/fimmu.2018.00458

8. Hansdottir S, Monick MM. Vitamin D effects on lung immunity and respiratory diseases. Vitam Horm. 2011;86:217-237.

9. Zu ZY, Jiang MD, Xu PP, et al. Coronavirus disease 2019 (COVID19): a perspective from China. Radiology. 2020;296(2):200490. doi:10.1148/radiol.2020200490

10. Martín Giménez VM, Inserra F, Tajer CD, et al. Lungs as target of COVID-19 infection: protective common molecular mechanisms of vitamin $\mathrm{D}$ and melatonin as a new potential synergistic treatment. Life Sci. 2020;254:117808. doi:10.1016/j.1fs.2020.117808

11. Zabetakis I, Lordan R, Norton C, Tsoupras A. COVID-19: the inflammation link and the role of nutrition in potential mitigation. Nutrients. 2020;12(5):1466. doi:10.3390/nu12051466 
12. Wang L, He W, Yu X, et al. Coronavirus disease 2019 in elderly patients: characteristics and prognostic factors based on 4-week follow-up. J Infect. 2020;80(6):639-645. doi:10.1016/j.jinf.2020.03.019

13. Entrenas Castillo M, Entrenas Costa LM, Vaquero Barrios JM, et al. Effect of calcifediol treatment and best available therapy versus best available therapy on intensive care unit admission and mortality among patients hospitalized for COVID-19: a pilot randomized clinical study. J Steroid Biochem Mol Biol. 2020;203:105751. doi:10. 1016/j.jsbmb.2020.105751

14. Im JH, Je YS, Baek J, Chung M-H, Kwon HY, Lee J-S. Nutritional status of patients with coronavirus disease 2019 (COVID-19). Int J Infect Dis. 2020;100:390-393. doi:10.1016/j.ijid.2020.08.018

15. De Smet D, De Smet K, Herroelen P, Gryspeerdt S, Martens GA. Vitamin D deficiency as risk factor for severe COVID-19: a convergence of two pandemics. MedRxiv. 2020.

16. Meltzer DO, Best TJ, Zhang H, Vokes T, Arora V, Solway J. Association of vitamin D deficiency and treatment with COVID-19 incidence. medRxiv. 2020. doi:10.1101/2020.05.08.20095893

17. D'Avolio A, Avataneo V, Manca A, et al. 25-hydroxyvitamin D concentrations are lower in patients with positive PCR for SARSCoV-2. Nutrients. 2020;12(5):1359. doi:10.3390/nu12051359

18. Kara M, Ekiz T, Ricci V, Kara Ö. 'Scientific strabismus' or two related pandemics: COVID-19 \& vitamin D deficiency. $\mathrm{Br} J$ Nutr. 2020;1-20.

19. Lau FH, Majumder R, Torabi R, et al. Vitamin D insufficiency is prevalent in severe COVID-19. medRxiv. 2020.

20. Panagiotou G, Tee SA, Ihsan Y, et al. Low serum 25-hydroxyvitamin D $(25[\mathrm{OH}] \mathrm{D})$ levels in patients hospitalized with COVID-19 are associated with greater disease severity. Clin Endocrinol (Oxf). 2020.

21. Ferrari D, Locatelli M, Briguglio M, Lombardi G. Is there a link between vitamin D status, SARS-CoV-2 infection risk and COVID19 severity? Cell Biochem Funct. 2020. doi:10.1002/cbf.3597
22. Carpagnano GE, Di Lecce V, Quaranta VN, et al. Vitamin D deficiency as a predictor of poor prognosis in patients with acute respiratory failure due to COVID-19. J Endocrinol Invest. 2020;1-7.

23. Ali N. Role of vitamin D in preventing of COVID-19 infection, progression and severity. J Infect Public Health. 2020;13(10):13731380. doi:10.1016/j.jiph.2020.06.021

24. Mendy A, Apewokin S, Wells AA, Morrow AL. Factors associated with hospitalization and disease severity in a racially and ethnically diverse population of COVID-19 patients. medRxiv. 2020.

25. Daneshkhah A, Eshein A, Subramanian H, Roy HK, Backman V. The role of vitamin D in suppressing cytokine storm in COVID-19 patients and associated mortality. medRxiv. 2020.

26. Merzon E, Tworowski D, Gorohovski A, et al. Low plasma $25(\mathrm{OH})$ vitamin D level is associated with increased risk of COVID-19 infection: an Israeli population-based study. FEBS J. 2020;287 (17):3693-3702. doi:10.1111/febs.15495

27. Fasano A, Cereda E, Barichella M, et al. COVID 19 in parkinson's disease patients living in Lombardy, Italy. Mov Disorders. 2020;35 (7):1089-1093. doi:10.1002/mds.28176

28. Raharusun P. Patterns of COVID-19 Mortality and Vitamin D: An Indonesian Study. Available at SSRN 3585561. 2020.

29. Raisi-Estabragh Z, McCracken C, Bethell MS, et al. Greater risk of severe COVID-19 in Black, Asian and minority ethnic populations is not explained by cardiometabolic, socioeconomic or behavioural factors, or by $25(\mathrm{OH})$-vitamin D status: study of 1326 cases from the UK Biobank. J Public Health (Bangkok). 2020;42(3):451-460. doi:10.1093/pubmed/fdaa095

30. Hastie CE, Mackay DF, Ho F, et al. Vitamin D concentrations and COVID-19 infection in UK Biobank. Diabetes Metab Syndr. 2020;14 (4):561-565. doi:10.1016/j.dsx.2020.04.050
Risk Management and Healthcare Policy

\section{Publish your work in this journal}

Risk Management and Healthcare Policy is an international, peerreviewed, open access journal focusing on all aspects of public health, policy, and preventative measures to promote good health and improve morbidity and mortality in the population. The journal welcomes submitted papers covering original research, basic science, clinical \& epidemiological studies, reviews and evaluations, guidelines, expert opinion and commentary, case reports and extended reports. The manuscript management system is completely online and includes a very quick and fair peer-review system, which is all easy to use. Visit http://www.dovepress.com/testimonials.php to read real quotes from published authors. 